\title{
Impact in Oral Cavity due to the Use of Hydrogen Peroxyde in Dental Treatment
}

\author{
Nanda Rachmad Putra Gofur ${ }^{1}$, Aisyah Rachmadani Putri Gofur ${ }^{2}$,Rizki Nur Rachman Putra Gofur ${ }^{3}$, Mega Kahdina ${ }^{3}$, \\ Hernalia Martadila Putri ${ }^{3}$ and Soesilaningtyas ${ }^{4}$ \\ ${ }^{1}$ Department of Health, Faculty of Vocational Studies, Universitas Airlangga, Indonesia \\ ${ }^{2}$ Faculty of Dental Medicine, Universitas Airlangga, Indonesia \\ ${ }^{3}$ Faculty of Medicine, Universitas Airlangga, Indonesia \\ ${ }^{4}$ Deptartment of Dental Nursing, Politeknik Kesehatan, Indonesia \\ *Corresponding author: Nanda Rachmad Putra Gofur, Department of Health, Faculty of Vocational Studies, Universitas Airlangga, \\ Indonesia
}

\begin{abstract}
Background: Chemicals agents are commonly found in people activities. It has a big role, especially in the oral cavity. The adverse effects that have been reported in cellular, animal and human studies include: chemical burn, cervical root resorption associated with non-vital bleaching; increased tooth sensitivity associated with vital bleaching; alteration in the surface topography of enamel; reduction in bond strength of resin based materials and the possibility that $\mathrm{H} 2 \mathrm{O} 2$ may have carcinogenic or tumor promoting capabilities Chemical agents are often used by people. But the chemical agents can cause the damage in human body such as oral cavity.

Objectives: To know the association between dental treatment and chemical burns in oral cavity.

Problem statement: In dental treatment, chemical agents are often used by dentist due to its function. But chemical agents can cause the damage in oral mucosa.

Discussion: One of the chemicals that is often found can cause chemical burn in oral mucosa is hydrogen peroxide. Hydrogen peroxides or $\mathrm{H}_{2} \mathrm{O}_{2}$ is used to decrease plaque formation and to control pyorrhea (gum inflammation). The mechanism of antimicrobial action is due to the release of nascent oxygen which is detrimental to anaerobes. It acts on both Gram positive and Gram-negative organism. $\mathrm{H}_{2} \mathrm{O}_{2}$ solutions usually do not result in severe toxicity but may cause vomiting; mild irritation to mucosa; and burns in the mouth, throat, oesophagus, and stomach. Ingestion of higher concentrations ( $>10 \%)$ can result in more dangerous sequelae, such as burns to mucus membranes and gut mucosa.
\end{abstract}

Conclusion: The use of chemical agents in dental treatment can cause the chemical burns in oral cavity. So, the patients need to listen more towards the dentist about the instruction after treatment so the materials cannot cause the irritation in oral mucosa.

Keywords: Oral cavity, chemical burn, dental treatment, hydrogen peroxide

\section{Introduction}

Chemicals agents are commonly found in people activities. It has a big role, especially in the oral cavity. Chemical agents are often used by people. But the chemical agents can cause the damage in human body such as oral cavity. Mucosal damage in the oral cavity can be iatrogenic during dental procedures, misuse or improper application of medicine and non-pharmaceutical substances by the patients. Chemicals that are often used in the oral cavity when dental care such as bleaching, restorations for restoration to dentures [1]. The practice of dentistry is very closely related to the use of chemicals. Inappropriate or excessive use of chemicals can cause damage to the oral mucosa. Clinical presentation of the chemical injuries might differ according to the composition 
and concentration, the $\mathrm{pH}$ of the substance, the quantity applied, the manner and duration of tissue contact, and the extent of penetration into tissue. These oral mucosal changes can vary from diffuse erosive lesions ranging from simple mucosal sloughing to complete mucosal detachment with extensions into the submucosa [2]. Dental treatments which were provided by dentists cannot be separated from chemical agents that actually have an impact on the body, but the dentists use them as needed so that often it does not have an impact on the oral mucosa. One of the chemicals that is often found can cause chemical burn in oral mucosa is hydrogen peroxide [3].

Hydrogen peroxide $\left(\mathrm{H}_{2} \mathrm{O}_{2}\right)$ is a colorless liquid with a bitter taste and is highly soluble in water to give an acidic solution. $\mathrm{H}_{2} \mathrm{O}_{2}$ is an oxidizing agent with a wide number of industrial applications in for example, bleaching or deodorizing textiles, wood pulp, hair, fur and foods, in the treatment of water and sewage, as a seed disinfectant and neutralizing agent in wine distillation. Low concentrations of $\mathrm{H} 2 \mathrm{O} 2$ have been found in rain and surface water, in human and plant tissues, in foods and beverages and in bacteria. Hydrogen peroxide is a reactive oxygen species, along with superoxide $\left(\mathrm{O}_{2}^{-}\right)$, hydroxyl (HO), peroxyl (ROO) and alkoxyl (RO). In human tissue, intrinsic sources of $\mathrm{H}_{2} \mathrm{O}_{2}$ are organelles (especially mitochondria), salivary cells, microorganisms, and the lungs. Hydrogen peroxide production can be followed by the liberation of highly reactive oxygen species in the body via enzymatic and spontaneous redox reactions that often involve interaction with transitional metals such as iron or copper [4]. Enzymes such as catalase, glutathione peroxidase and superoxide dismutase catalyze the decomposition of $\mathrm{H}_{2} \mathrm{O}_{2}$ into water and oxygen. Reactive oxygen radicals are a potential source of cell damage through causing DNA strand breaks, genotoxicity, and cytotoxicity, but these radicals tend neither to cross biological membranes nor travel large distances within a cell. Antioxidants provide a source of electrons that reduce hydroxyl radicals to water. However, when exogenous $\mathrm{H}_{2} \mathrm{O}_{2}$ levels overwhelm cellular protective mechanisms, $\mathrm{H}_{2} \mathrm{O}_{2}$ presents a health hazard. Individuals with catalase lack catalase activity, leading to high endogenous $\mathrm{H}_{2} \mathrm{O}_{2}$ levels causing necrosis and ulceration of soft and hard tissues [5]. Hydrogen peroxides or $\mathrm{H}_{2} \mathrm{O}_{2}$ is used to decrease plaque formation and to control pyorrhea (gum inflammation). The mechanism of antimicrobial action is due to the release of nascent oxygen which is detrimental to anaerobes. It acts on both Gram positive and Gram-negative organism. The other mechanism of antimicrobial property is the effect of $\mathrm{H}_{2} \mathrm{O}_{2}$ on debridement of bacterial cell walls [6]. It is widely used professional and self-administered dental product. The most common applications of $\mathrm{H}_{2} \mathrm{O}_{2}$ include Mouth rinse $(1 \%-3 \%)$ and bleaching agent $(3 \%-5 \%)$. As patients' needs for aesthetic dental treatment shift from traditional treatment including caries and dentures to esthetic treatment, an increasing number of people are visiting the dental office with hopes for whiter teeth. Over the counter (OTC) bleaching products are sold as cosmetics and are freely available through stores, pharmacies, and the Internet. Although in-office bleaching is a particularly popular method for bleaching, the bleaching agent may sometimes come into contact with the patient's gingiva or oral mucosa during the in-office bleaching procedure, even if the gingiva is protected with a light-cured resin or rubber dam and bleaching is performed by an experienced dentist. This may result in temporary whitening and pain in the gingiva or oral mucosa, but the pain subsides within a few hours and the whitened spot eventually regains its original color. This has also been reported with at-home bleaching $[7,8]$ (Table 1).

Table 1: Exposure to Hydrogen Peroxide.

\begin{tabular}{|c|c|c|}
\hline Situation & $\begin{array}{c}\text { Concentration } \\
\text { used \% }\end{array}$ & $\begin{array}{c}\text { Duration of } \\
\text { Exposure }\end{array}$ \\
\hline $\begin{array}{c}\text { In-office bleaching (tooth } \\
\text { surface) }\end{array}$ & $30-35$ & 5 Minutes \\
\hline $\begin{array}{c}\text { Bleaching of stained root- } \\
\text { filled tooth }\end{array}$ & $30-35$ & 30 Minutes \\
\hline "Walking beach " & 3.5 & 8 Hours \\
\hline Mouth rinse & $1-3$ & 5 Minutes \\
\hline Dentifrice & 0.75 & 5 Minutes \\
\hline
\end{tabular}

A study investigate the toxicity of in-office bleaching agents on gingiva, Hydrogen peroxide can be toxic in high concentrations and with exposures of prolonged duration, concentrated (3035 per cent) hydrogen peroxide solutions have been used for inoffice bleaching treatments with had adverse soft and hard tissue effects observed clinically, one of them might be chemical burn. Nevertheless, there have been occasions when accidental ingestion of hydrogen peroxide products in the home has led to hospitalization and adverse health outcomes, and this should be kept in mind when assessing the relative safety of hydrogen peroxide-containing products for home (unsupervised) use. Concerns have been expressed over the potential adverse effects of the use of $\mathrm{H}_{2} \mathrm{O}_{2}$ in dental treatment. The adverse effects that have been reported in cellular, animal and human studies include: chemical burn, cervical root resorption associated with non-vital bleaching; increased tooth sensitivity associated with vital bleaching; alteration in the surface topography of enamel; reduction in bond strength of resin based materials and the possibility that $\mathrm{H}_{2} \mathrm{O}_{2}$ may have carcinogenic or tumor promoting capabilities $[9,10]$. Aim of this article is to know the association between dental treatment and chemical burns in oral cavity due to chemical agents used especially impact $\mathrm{H}_{2} \mathrm{O}_{2}$.

\section{Discussion}

The response of mammalian cells to $\mathrm{H}_{2} \mathrm{O}_{2}$ is highly variable, dependent on factors such as catalase concentration and DNA repair activity. In one study, $\mathrm{H}_{2} \mathrm{O}_{2}$ induced a dose-dependent increase of hypoxanthine guanine phosphoribosyl transferase (HPRT) mutations in vitro in human T lymphocytes, most mutations being of the same kind as observed in T cells in vivo. Another study, using 
human lymphocytes, assessing genotoxicity showed the main event induced by extracellular application of $\mathrm{H}_{2} \mathrm{O}_{2}$ to be necrosis and not micronucleus formation $[10,11]$.

\section{Stomatitis}

Oral ingestion of $3 \% \mathrm{H}_{2} \mathrm{O}_{2}$ solutions usually do not result in severe toxicity but may cause vomiting; mild irritation to mucosa; and burns in the mouth, throat, oesophagus, and stomach. Ingestion of higher concentrations $(>10 \%)$ can result in more dangerous sequelae, such as burns to mucus membranes and gut mucosa. It shows a dose-dependent reaction where at high concentration eugenol causes adverse effect on fibroblast-.and osteoblasts-like cells. This leads to localized necrosis and compromised healing. In lower concentration, it causes localized hypersensitivity reactions to oral mucosa called "contact stomatitis" and on dermis causes "contact dermatitis," possibly because it can react directly with proteins to form conjugates and reactive happens $[5,11]$
(Figure 1). Study before found that almost no cytotoxicity from $\mathrm{H}_{2} \mathrm{O}_{2}$ was seen in the low-concentration stimulation group $(1.5 \times$ $10-3 \%$ or less) at any duration other than 60 minutes. However, 60-minute stimulation resulted in cytotoxicity at all concentrations. Stimulation at $15 \% \mathrm{H}_{2} \mathrm{O}_{2}$, which is similar to the concentration used in clinical practice, showed marked cytotoxicity, lowering cell survival by half at 90 seconds $(p<0.05)$, which is the shortest time period examined. Using the same stimulation samples as in the section above, microarray was used to analyze the gene clusters that were suppressed from the addition of vitamin E among the gene cluster induced by $\mathrm{H}_{2} \mathrm{O}_{2}$ stimulation. The results confirmed that $\mathrm{H}_{2} \mathrm{O}_{2}$ stimulation induced the expression of genes associated with the proinflammatory cytokine TNF- $\alpha$ cascade. Expression of these genes was suppressed with vitamin $\mathrm{E}$ addition. These results demonstrate that $\mathrm{H}_{2} \mathrm{O}_{2}$ stimulation response includes triggering the proinflammatory cytokine TNF- $\alpha$ cascade and that addition of vitamin E suppresses the response of this cascade [12,13].

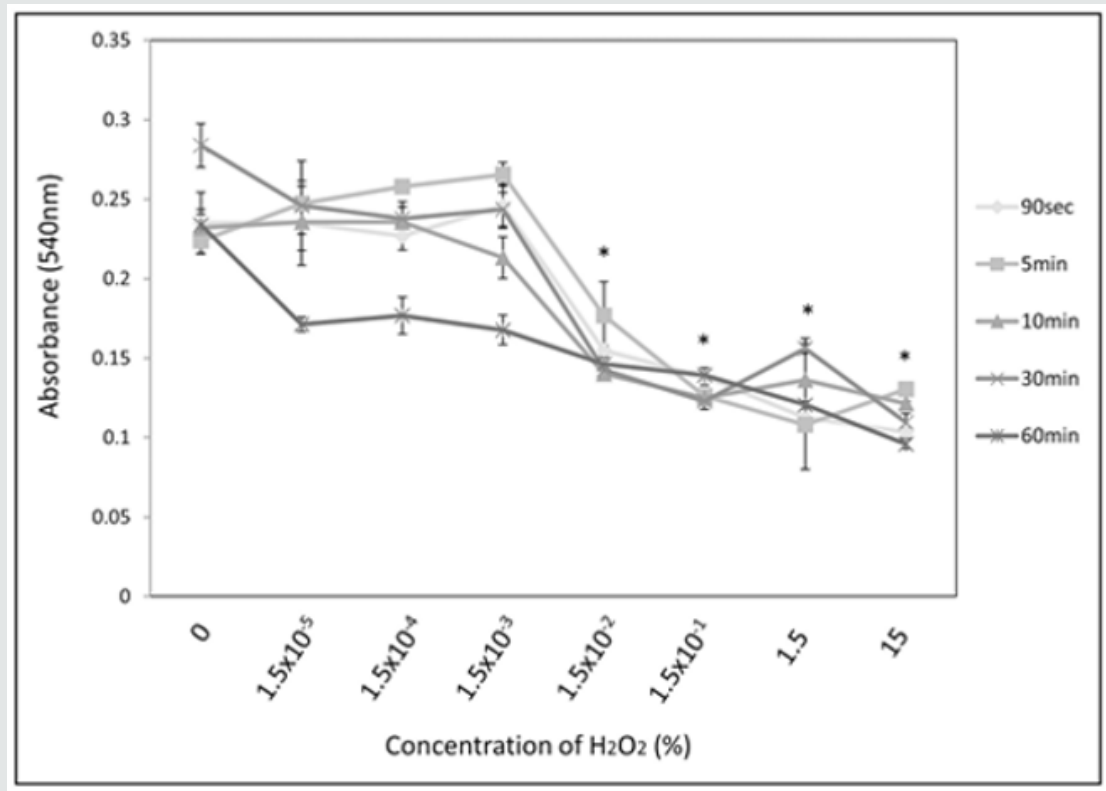

Figure 1: Concentration of $\mathrm{H}_{2} \mathrm{O}_{2}$ and its absorbance.

\section{Gingival inflammation}

Study in vitro examinations of signs such as whitening of the gingiva and pain that may result from tooth whitening. No studies to this effect in HGFs have been reported from at-home bleaching agents but mostly result from in-office bleaching agents and OTC products. Many studies have been carried out on tooth hypersensitivity from in-office or at-home bleaching agents. From in vitro studies, it has been concluded that whitening agents histologically penetrate the dentin and do not damage the pulp. In current dental practice, pain incurred during the procedure is generally treated with medication or fluoride or by stopping the procedure. Several studies examining plaque control as an index have shown that whitening agents reduce plaque on the gingiva and reduce gingival inflammation. Hydrogen peroxide and carbamide peroxide have been used for debridement during endodontic therapy, in mouth rinses to reduce plaque in individuals with gingivitis, and for treatment of periodontal diseases [13,14]. Gingival fibroblasts are known to be affected by $\mathrm{H}_{2} \mathrm{O}_{2}$. However, studies have shown that fibroblasts in other parts of the body are more strongly affected. In the present study, highly concentrated $\mathrm{H}_{2} \mathrm{O}_{2}$ caused inflammation in gingival fibroblasts and had toxic effects, with marked changes in cell morphology. One study found that higher concentrations of $\mathrm{H}_{2} \mathrm{O}_{2}$ caused senescence-like changes in cells. It has long been known from in vivo animal experiments that $\mathrm{H}_{2} \mathrm{O}_{2}$ causes acute inflammation and even edema in skin. Simon and other have shown $\mathrm{H}_{2} \mathrm{O}_{2}$ to cause necrosis in human 
fibroblasts. Cells are protected by various types of enzymes and other substances and manage the immune system that responds to inflammation. Inferring from the above studies, it is possible that $\mathrm{H}_{2} \mathrm{O}_{2}$ penetrates the cell membrane to cause damage, so that enzymes cannot do their job $[15,16]$.

\section{Chemical burn}

Recent studies have reported gingival irritation and chemical burn after at-home bleaching. Kirsten and others reported that patients experienced gingival irritation from at-home bleaching both immediately after the procedure and up to 45 days following treatment. Another study reported that hypersensitivity and gingival irritation disappeared within two days after in-office bleaching. Previous investigations have shown that $15 \%$ of patients reported gingival irritation after in-office bleaching, but it was possible to safely control contact of the bleaching gel with the gingival margin by using light-cured gingival dams $[17,18]$. Among the human genes listed in Table 2, TNFSF10 belongs to the tumor necrosis factor (TNF)- $\alpha$ ligand superfamily. TNFRSF4 and TNFRSF19 belong to the TNF- $\alpha$ receptor superfamily (TNFRSF). Other authors have examined the gingiva and proinflammatory cytokines. Two types of in-office were examined for bleaching agent and one type of at-home bleaching agent. Found that interleukin (IL)-1 $\beta$ expression increased with in-office bleaching but that there was no change in the expression of IL-10. In inflamed tissue, macrophages and other cells of the innate immune system synthesize TNF- $\alpha$, a proinflammatory cytokine, to fight off infection and treat tissue damage. This TNF- $\alpha$ then binds to cell surface receptors and induces the production of other cytokines, triggering and maintaining inflammation. It is possible that $\mathrm{H} 2 \mathrm{O} 2$ came into contact with the gingiva triggered a cellular response through the inflammatory cascade via TNF- $\alpha$ resulting in chemical burn $[19,20]$.

Table 2: Correlation between $\mathrm{H} 2 \mathrm{O} 2$ and its impact to human gene.

\begin{tabular}{|c|c|c|c|}
\hline Name of Case & Function & $\mathrm{H}_{2} \mathbf{O}_{2}$ & Vitamin E \\
\hline \multirow{2}{*}{$\begin{array}{l}\text { Homo Sapiens cation channel, sperm associated } 2 \\
\text { (CATSPER2) }\end{array}$} & Protein binding & \multirow{2}{*}{2.844} & \multirow{2}{*}{-2.638} \\
\hline & Voltage-gated calcium channel activity & & \\
\hline Hamo sapiens calsyntenin 3 (CLSTN3) & Calcium ion binding & 2.04 & -2.681 \\
\hline Hamo sapiens deleted in liver cancer 1 (DLC1) & Protein binding & 1.68 & -1.55 \\
\hline Hamo sapiens ephrin-B3 (EFNB3) & Axon guidance & 1.68 & -1.81 \\
\hline Hamo sapiens Fc receptors-like 5 (FCRL5) & $\begin{array}{l}\text { Receptor activity association to } \\
\text { decrease }\end{array}$ & 3.84 & -3.3 \\
\hline Hamo sapiens growth hormone 1 (GH1) & Cytokine-cytokine receptor interaction & 1.90 & -2.053 \\
\hline $\begin{array}{l}\text { Hamo sapiens guanine nucleotide binding protein (G } \\
\text { protein) }\end{array}$ & GTPase activity & 1.745 & -1.669 \\
\hline Hamo sapiens Kinesin family member 26A (KIF26A) & ATP binding & 1.99 & -4.39 \\
\hline Hamo sapiens Kruppel-like factor 6 (KLF6) & DNA binding & 1.776 & -1.55 \\
\hline $\begin{array}{c}\text { Hamo sapiens nuclear receptor subfamily } 1 \text {, group } \mathrm{H} \text {, } \\
\text { member } 4(\mathrm{NR} 1 \mathrm{H} 4)\end{array}$ & Protein activity & 3.054 & -2.50 \\
\hline \multirow{2}{*}{$\begin{array}{l}\text { Hamo sapiens olfactory receptor, family } 2 \text {, subfamily } \mathrm{H} \text {, } \\
\text { member } 1(\mathrm{OR} 2 \mathrm{H} 1)\end{array}$} & G-protein occupied receptor activity & \multirow{2}{*}{2.629} & \multirow{2}{*}{-2.23} \\
\hline & Olfactory receptor activity & & \\
\hline $\begin{array}{l}\text { Hamo sapiens olfactory receptor, family } 3 \text {, subfamily A, } \\
\text { member } 4 \text { oseudogene (OR3A4P) }\end{array}$ & Oderant receptor & 2.132 & -1.76 \\
\hline Hamo sapiens outer dense fiber of sperm tails 4 (ODF4) & Unknown & 2.4745 & -2.015 \\
\hline \multirow{3}{*}{$\begin{array}{l}\text { Hamo sapiens phosphate, regulating endopeptidase homolog } \\
\qquad \text { X-linked (PHEX) }\end{array}$} & Zion ion activity & \multirow{3}{*}{1.562} & \multirow{3}{*}{-1.53} \\
\hline & Aminopeptidase activity & & \\
\hline & Metalloendopeptise activity & & \\
\hline Hamo sapiens phospholipase C, zeta 1 (PLCZ1) & Calcium ion binding & 3.205 & -2.879 \\
\hline Hamo sapiens POU class 4 homeobox 1 (PQU4F1) & $\begin{array}{l}\text { DNA binding transcription factor } \\
\text { activity }\end{array}$ & 2.968 & -2.618 \\
\hline $\begin{array}{l}\text { Hamo sapiens RUN domain containing 3B (RUNDC3B), } \\
\text { transcript variant } 1\end{array}$ & Unknown & 2.647 & -1.962 \\
\hline $\begin{array}{l}\text { Hamo sapiens scavenger receptor cysteine rich domain } \\
\text { containing ( } 5 \text { domains) (SSC5D) }\end{array}$ & Scavenger receptor activity & 1.518 & -1.862 \\
\hline Hamo sapiens small nuclear RNA, C/D box 88C (SNCRDB8C) & Unknown & 2.088 & -2.51 \\
\hline Hamo sapiens small nuclear RNA, H/ACA, box 30 (SNORA30) & Unknown & 1.82 & -1.92 \\
\hline Hamo sapiens transcription factor 20 (AR1) (TCF20) & DNA binding & 1.58 & -1.70 \\
\hline
\end{tabular}




\begin{tabular}{|c|c|c|c|}
\hline Hamo sapiens transmembrane protein 236 (TMEM236) & Unknown & 2.72 & -2.24 \\
\hline $\begin{array}{c}\text { Hamo sapiens tumor necrosis factor (ligand) superfamily, } \\
\text { member 10 (TNFSF10) }\end{array}$ & Cytokine-cytokine receptor interaction & -2.920 & 2.268 \\
\hline $\begin{array}{c}\text { Hamo sapiens tumor necrosis factor (ligand) superfamily, } \\
\text { member 19 (TNFSF19) }\end{array}$ & Cytokine-cytokine receptor interaction & 2.667 & -1.62 \\
\hline $\begin{array}{c}\text { Hamo sapiens tumor necrosis factor (ligand) superfamily, } \\
\text { member 4 (TNFSF4) }\end{array}$ & Cytokine-cytokine receptor interaction & 1.518 & -2.454 \\
\hline $\begin{array}{c}\text { Hamo sapiens V-set and transmembrane domain containing } \\
\text { 2 like (VSTM2L) }\end{array}$ & Protein binding & 2.018 & -1.790 \\
\hline $\begin{array}{c}\text { Hamo sapiens zine finger and BTB domain containing 22 } \\
\text { (ZBTB22) }\end{array}$ & DNA binding, zinc ion binding & 2.057 & -1.864 \\
\hline Netrin G1 & Protein binding & \\
\hline
\end{tabular}

\section{Carcinoma potential}

Another study also reported that using hydrogen peroxide and alcohol on a daily/weekly basis encourages the promotion of malignant neoplasm in the oral mucosa. Alcohol, for instance, potentiates in 50 times the harm caused by tobacco. Mouth washing with hydrogen peroxide, using products made with alcohol or drinking alcohol everyday may lead to the risk of oral chemical carcinogenesis. Also known as urea peroxide, sodium perborate, carbamide peroxide or other less common names, the hydrogen peroxide may have deleterious effects on the enamel, dentin, cementum, pulp and gingiva [6]. These names vary according to the presentation and formulation of the product. However, if both formulation and presentation of the product are controlled, and if the product is properly applied by a professional who takes the appropriate compensatory measures, its use is safe. In the oral mucosa, hydrogen peroxide potentiates the effect of many other carcinogenic agents found in patient's mouth. These carcinogenic agents may originate from food, cosmetics, hygiene products, pesticides, herbicides, tobacco, alcohol, virus, among others. Such potentiation happens due to the fact that these products are promoting agents of oral chemical carcinogenesis [21]. In mice low doses of hydrogen peroxide $(0.1 \%$ and $0.4 \%)$ administered in drinking water caused adenomas or adenocarcinomas in the duodenum. These findings have been questioned and it has been proposed that the most likely cause of the lesions observed were the decreased water consumption of the mice and resultant abrasion of the luminal lining on ingestion of pelleted dry rodent food. Another animal study suggested that a known tobacco carcinogen 9, 10-dimethyl-1, 2-benzanthracene (DMBA) could be augmented in producing carcinogenesis in the buccal epithelium of hamsters by $3 \% \mathrm{H}_{2} \mathrm{O}_{2}$. These results have been disputed due to the small number of animals studied. Further studies in hampsters given up to $70 \mathrm{mg} /$ $\mathrm{kg}$ of $\mathrm{H}_{2} \mathrm{O}_{2}$ by oral intubation for up to six months or up to $3 \% \mathrm{H}_{2} \mathrm{O}_{2}$ in combination with DMBA applied five times daily for 16-20 weeks on the buccal epithelium did not show any sign of carcinogenesis. Further studies on skin have concluded that $\mathrm{H}_{2} \mathrm{O}_{2}$ is inactive as a tumour promoter or carcinogen $[22,23]$.

\section{Impact in root resorption and tooth sensitivity}

An adverse effect that has been reported following internal tooth bleaching is cervical root resorption (an inflammatorymediated external resorption of the root). Summarizes the available data to support a correlation between internal tooth bleaching and cervical root resorption. In these cases, it is very difficult to distinguish if the root resorption noted was due to the effect of the bleach or the trauma [21,24]. A high concentration of hydrogen peroxide in combination with heating seems to promote cervical root resorption. The underlying mechanism for this effect is unclear, but it has been suggested that the bleaching agent reaches the periodontal tissues through the dentinal tubules and initiates an inflammatory reaction. In vitro studies using extracted teeth showed that hydrogen peroxide placed in the pulp chamber penetrated the dentine, that heat increased the penetration and that the penetration is greater in teeth with cervical cemental defects. Intracorneal bleaching with $30 \%$ hydrogen peroxide reduces the micro-hardness of dentine and enamel and mechanically weakens the dentine $[5,19]$.

Case reports and small clinical studies have confirmed that a $10 \%$ carbamide peroxide gel used in a bleaching tray at night, (the so-called nightguard vital bleaching technique), produces predictable tooth whitening as do $\mathrm{H}_{2} \mathrm{O}_{2}$ strips and 'power bleaching' using $35 \% \mathrm{H}_{2} \mathrm{O}_{2}$ with or without light and/or heat activation. Tooth sensitivity is a common adverse effect of external tooth bleaching. Data from various studies of $10 \%$ carbamide peroxide indicate that from $15-65 \%$ of patients reported increased tooth sensitivity. Higher incidences of tooth sensitivity (from 67-78\%) were reported after bleaching with $\mathrm{H}_{2} \mathrm{O}_{2}$ in combination with heat $[22,25]$. There are many carcinogenic products available for sale, for instance: alcoholic beverages, cigarettes, ground tobacco, medicines, insecticides and others. These products are sold directly to the consumer after warnings and awareness campaigns had been carried out. That is how democracy works; products are sold directly to the consumers, but with a wide range of awareness, classification and explanatory campaigns stating that these products are carcinogenic. Hydrogen 
peroxide reddens the mucosa and gingiva by wounding them with tissue dissolution and inflammation. Hydrogen peroxide burns and may lead to necrosis of gingival papillae. It completely cleans the teeth because it demineralizes the enamel and also removes dirt or pigments. The enamel becomes porous and food stains it even more, increasing the need for mouth washing. Enamel becomes thicker every day. Should there be any restoration, it will induce microleakage through its interface with the tooth, causing the enamel to come out easily while eating $[22,26]$.

If burning the mucosa and demineralizing the enamel were the biggest problems, we could think about using hydrogen peroxide with moderation. However, the biggest problem is that hydrogen peroxide is a promoting agent. In other words: it potentiates the effect of inducers of oral, throat, esophagus, stomach, and intestine cancer. Pesticides, tobacco products, alcohol, HPV and other oncogenic viruses, sunray and chemicals found in industrialized food are potentiated by hydrogen peroxide. Many doctoral dissertations, master's thesis, research and books confirm what the literature has already proved by means of different methodologies. In vivo chemical carcinogenesis experiments prove the carcinogenic effect of hydrogen peroxide on the mucosa that receives tooth bleaching products, antiseptics, and toothpaste [20,27]. Dental bleaching is based on the ability of $\mathrm{H}_{2} \mathrm{O}_{2}$ to penetrate through tooth structure and produce free radicals to oxidize the colored organic molecules. There are many reports investigated the effect of dose and exposure time of $\mathrm{H}_{2} \mathrm{O}_{2}$ to the pulpal tissues as the bleaching agents penetrated through the tooth structure. The safety of $\mathrm{H}_{2} \mathrm{O}_{2}$ tooth bleaching is still controversial: its genotoxicity and carcinogenicity are under active discussion. Diaz-Llera et al. showed that 0.34-1.35 $\mu \mathrm{M}$ of $\mathrm{H}_{2} \mathrm{O}_{2}$ induced hypoxanthine guanine phosphoribosyl transferase (HPRT) mutation both in vitro and in vivo. High-dose $\mathrm{H}_{2} \mathrm{O}_{2}$ was reported to be mildly carcinogenic for the duodenum of catalase-deficient mice. In another report, $1 \% \mathrm{H}_{2} \mathrm{O}_{2}(\sim 0.3 \mathrm{M})$ in drinking water induced forestomach tumors in rats. These reports showed that exposure to high-dose $\mathrm{H}_{2} \mathrm{O}_{2}$ for a sustained period induces oxidative stress that leads to DNA damage in mammalian cells [26,27].

\section{Conclusion}

The use of chemical agents in dental treatment can cause the chemical burns in oral cavity. So, the patients need to listen more towards the dentist about the instruction after treatment so the materials cannot cause the irritation in oral mucosa.

\section{References}

1. Girish MS, Anandakrishna L, Chandra P, Nandlal B, Srilatha KT (2015) Iatrogenic injury of oral mucosa due to chemicals: A case report of formocresol injury and review. IOSR J Dent Med Sci 14: 1-5.

2. Vucicevic Boras V, Brailo V, Andabak Rogulj A, Vidovic Juras D, Gabric D, et al. (2015) Oral adverse reactions caused by over-the-counter oral agents. Case Rep Dent 2015: 196292.

3. Dilsiz A (2010) Self-inflicted oral soft-tissue burn due to local behavior and treatment. J Clin Exp Dent 2: e51-54.
4. Rashed HT (2016) Evaluation of the effect of hydrogen peroxide as a mouthwash in comparison with chlorhexidine in chronic periodontitis patients: A clinical study. Journal of International Society of Preventive \& Community Dentistry 6(3): 206-212.

5. Tredwin C, Naik S, Lewis N (2006) Hydrogen peroxide tooth-whitening (bleaching) products: Review of adverse effects and safety issues. $\mathrm{Br}$ Dent J 200(7): 371-376

6. Putt MS, Proskin HM (2013) Custom tray application of peroxide gel as an adjunct to scaling and root planing in the treatment of periodontitis: Results of a randomized controlled trial after six months. J Clin Dent 24 . 100-107.

7. Shetty K (2006) Hydrogen peroxide burn of the oral mucosa. Ann Pharmacother 40(2): 351.

8. Furukawa M (2015) Cytotoxic Effects of Hydrogen Peroxide on Human Gingival Fibroblasts In Vitro. Oper Dent 40(4): 430-439.

9. Walls LJ (2000) Safety issue relating to the use of hydrogen peroxide in dentistry. Australia Dental Journal (4): 257-269.

10. Lin K, Chung C, Ciou J (2019) Molecular damage and responses of oral keratinocyte to hydrogen peroxide. BMC Oral Health 19: 10.

11. Sulieman MA (2008) An overview of tooth-bleaching techniques: chemistry, safety and efficacy. Periodontol 2000 48: 148-169.

12. Esberard R, Esberard R, Esberard RM, Consolaro A, Pameijer CH (2007) Effect of bleaching on the cemento-enamel junction. Am J Dent 20(4): 245-249.

13. Li Y, Greenwall L (2013) Safety issues of tooth whitening using peroxidebased materials. Br Dent J 215(1): 29-34.

14. Consolaro, Alberto (2013) Mouthwashes with hydrogen peroxide are carcinogenic but are freely indicated on the internet: warn your patients. Dental Press Journal of Orthodontics 18(6): 5-12.

15. Munro IC, Williams GM, Heymann HO (2006) Tooth whitening products and the risk of oral cancer. Food Chem Toxicol 44(3): 301-315.

16. Francischone LA, Consolaro A (2008) Morphology of the cementoenamel junction of primary teeth. J Dent Child (Chic) 75(3): 252-259.

17. Neuvald L, Consolaro A (2000) Cementoenamel junction: microscopic analysis and external cervical resorption. J Endod 26(9): 503-508.

18. Naik S, Tredwin CJ, Scully C (2006) Hydrogen peroxide tooth-whitening (bleaching): review of safety in relation to possible carcinogenesis. Oral Oncol 42(7): 668-674.

19. Cadet J, Douki T, Gasparutto D (2003) Oxidative damage to DNA: formation, measurement, and biochemical features. Mutat Res 531(12): 5-23.

20. Alqahtani MQ (2014) Tooth-bleaching procedures and their controversial effects: A literature review. Saudi dent J 26(2): 33-46.

21. Calenic B, Greabu M, Caruntu C, Tanase C, Battino M (2015) Oral keratinocyte stem/progenitor cells: specific markers, molecular signaling pathways and potential uses. Periodontol 2000 69(1): 68-82.

22. Squier CA, Nanny D (1985) Measurement of blood flow in the oral mucosa and skin of the rhesus monkey using radiolabelled microspheres. Arch Oral Biol 30(4): 313-318.

23. Torres CR, Souza CS, Borges AB, Huhtala MF, Caneppele TM (2013) Influence of concentration and activation on hydrogen peroxide diffusion through dental tissues in vitro. Sci World J 2013: 193241.

24. Ballinger SW, Patterson C, Yan CN (2000) Hydrogen peroxide- and peroxynitrite-induced mitochondrial DNA damage and dysfunction in vascular endothelial and smooth muscle cells. Circ Res 86(9): 960-966.

25. Mahony C, Barker ML, Engel TM (2003) Peroxide degradation kinetics of a direct application percarbonate bleaching film. Am J Dent 16(Spec No): 9B-11B.

26. Boras (2015) Oral Adverse Reactions Caused by Over-the-Counter Oral Agents. Case Report in Dentistry 196292(4). 
CC $(2)$ This work is licensed under Creative

To Submit Your Article Click Here: Submit Article

DOI: $10.32474 /$ IPDOAJ.2020.04.000199

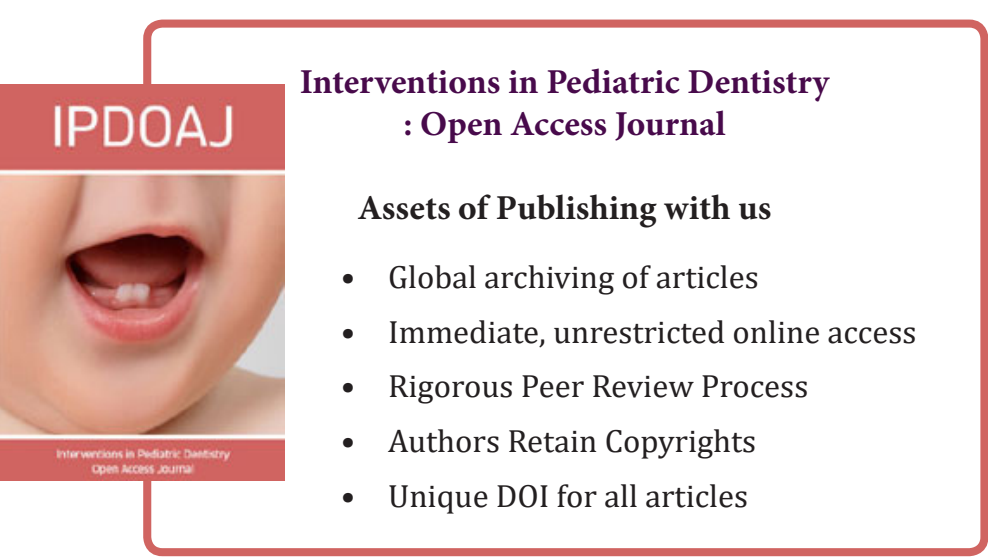

